\title{
Estabilidade microbiológica e físico-química de misturas para bolo sem glúten e qualidade dos bolos prontos para consumo
}

\author{
Microbiological and physicochemical stability of gluten-free cake \\ mixtures and quality of ready cakes for consumption
}

Autores | Authors

Luciana de Oliveira Froes

GOMES

Universidade Federal de Goiás (UFG)

Escola de Agronomia e Engenharia de Alimentos

Programa de Pós-Graduação em Ciência e Tecnologia de Alimentos Goiânia/GO - Brasil e-mail: lu@froes.org

\section{Raquel de Andrade Cardoso} SANTIAGO

Universidade Federal de Goiás (UFG) Faculdade de Nutrição Goiânia/GO - Brasil e-mail: rcardosu@fanut.ufg.br

\section{Selma Nakamoto KOAKUZU}

EMBRAPA Arroz e Feijão Laboratório de Grãos e Subprodutos

Santo Antônio de Goiás/GO - Brasil e-mail: selma.nakamoto@embrapa.br

\section{凶 Priscila Zaczuk BASSINELLO*}

EMBRAPA Arroz e Feijão Laboratório de Grãos e Subprodutos Rodovia GO-462, Km 12, Zona Rural Caixa Postal: 179 CEP: 75375-000

Santo Antônio de Goiás/GO - Brasil e-mail: priscila.bassinello@embrapa.br

\ Autor Correspondente / Corresponding Author

Recebido / Received: Abr. 11, 2014 Aprovado / Approved: Jan. 28, 2015

\section{Resumo}

O objetivo deste trabalho foi avaliar a estabilidade microbiológica e físico-química de misturas para bolo sem glúten armazenadas por 240 dias, bem como a qualidade dos respectivos bolos prontos. As formulações sem glúten continham farinha de quirera de arroz crua (FAC) e farinha de bandinha de feijão extrusada (FFE) em substituição total à farinha de trigo, preparadas com $45 \%$ e $75 \%$ de FFE. As farinhas e as misturas para bolo (MB) foram analisadas quanto ao teor de umidade, atividade de água, $\mathrm{pH}$, acidez total titulável, cor e qualidade microbiológica, conforme técnicas padronizadas. Para os bolos assados avaliou-se a aceitabilidade sensorial, o volume específico, a textura, além da cor e qualidade microbiológica. Os resultados foram submetidos à análise de variância e de componentes da variância, ao teste múltiplo de comparação de médias (Duncan, $5 \%$ de probabilidade), ao teste de correlação de Pearson e, quando possível, foi determinada a equação de regressão. As MB sem glúten apresentaram boa estabilidade ao longo do armazenamento, sendo que não houve variação significativa do teor de umidade (variação máxima de 0,7\%) e a atividade de água permaneceu sempre abaixo de 0,6, valor ideal para impedir desenvolvimento microbiano. A cor das misturas para bolo sem glúten não sofreu influência significativa do tempo, refletindo na prática em estabilidade mais prolongada da cor dos produtos finais para consumo. Quanto aos bolos prontos para o consumo, aquele com $75 \%$ de FFE se destacou pelo aumento percentual significativo de até $25,75 \%$ do volume específico. Contudo, todos os bolos foram aceitos (escores $>6$ ) em todos os atributos analisados durante todo o período de armazenamento das misturas. As farinhas e misturas para bolo com FFE podem ser armazenadas até oito meses à temperatura ambiente sem sofrer alterações microbiológicas e físico-químicas que afetem a qualidade dos produtos, inclusive as características tecnológicas e sensoriais dos bolos.

Palavras-chave: Oryza sativa; Phaseolus vulgaris; Armazenamento; Doença celíaca; Farinha de quirera de arroz; Farinha de bandinha de feijão extrusada. 


\section{Summary}

The aim of this study was to evaluate the microbiological and physicochemical stability of mixtures for gluten-free cake, stored for 240 days, as well as, the quality of their baked cakes. The gluten-free formulations contain flour of broken rice (FAC) and extruded broken beans (FFE) in total replacement of wheat flour, which were prepared with $45 \%$ and $75 \%$ of FFE. The flours and mixtures for cakes (MB) were analyzed for the levels of moisture, water activity, $\mathrm{pH}$, acidity, color and microbiological quality, according to standard techniques. The baked cakes were evaluated for the sensory analyzes, specific volume, texture, beyond the color and microbiological quality. The results were submitted to the analysis of variance and variance components, Duncan's multiple test for means comparison (probability of 5\%), Pearson's correlation and when possible, analysis of regression. The gluten-free MB showed good stability during storage, without significant variation in moisture content (maximum variation of $0.7 \%$ ) and water activity always remained below 0.6 , optimal value for preventing microbial growth. The color of the mixtures for gluten-free cake had no influence of time, reflecting on practice in longer color stability of the final products. As for baked cakes, the one with $75 \%$ of FFE is highlighted by the mean percentage increase of up to $25.75 \%$ of the specific volume. However, all cakes were accepted (scores $>6$ ) for all attributes analyzed during the storage period of the mixtures. The flours and cake mixtures can be stored for up to eight months at room temperature without undergoing microbiological and physicochemical changes that affect the quality of the products, including technological and sensory characteristics of the cakes.

Key words: Oryza sativa; Phaseolus vulgaris; Storage; Celiac disease; Broken rice flour; Broken bean extruded flour. 


\section{Introdução}

Mudanças no processamento e a crescente exigência do consumidor de alimentos com qualidades sensoriais, nutricionais e que tragam benefícios à saúde incentivam o estudo de novos ingredientes para a indústria alimentícia, inclusive de novas versões de produtos que antes eram condenados em qualquer dieta como, por exemplo, os bolos (MOSCATTO et al., 2004). No grupo de bolos industrializados encontram-se as misturas para bolo, obtidas a partir da homogeneização de dois ou mais ingredientes secos e de fácil elaboração, apenas com a simples adição dos produtos líquidos (ovo, leite, óleo) e assamento. As vantagens na comercialização da mistura para bolo em relação ao bolo pronto para consumo se destacam pela maior vida útil do produto, pela facilidade de transporte e manuseio e pela diversificação do produto (BORGES et al., 2010).

Conforme Borges et al. (2006), as técnicas de processamento e obtenção das misturas prontas para bolo estão sempre evoluindo, pois as exigências dos consumidores de alimentos com qualidade sensorial incentivam o estudo de novos ingredientes para pré-misturas. As características desejáveis do bolo, como maciez e superfície lisa, são de responsabilidade das proteínas formadoras do glúten (glutenina e gliadina); o alimento com melhor qualidade do glúten é o trigo, o principal ingrediente para produtos panificados. No entanto, diversos estudos já têm mostrado a possibilidade de substituição da farinha de trigo por farinhas de outros cereais ou, ainda, de leguminosas, inclusive para elaboração de produtos sem glúten, a fim de atender um mercado específico, dos doentes celíacos (CARVALHO et al., 2012a; GULARTE et al., 2012; SILVA et al., 2009; SOUZA, 2011).

Dentre cereais e leguminosas, o arroz e o feijão, respectivamente, destacam-se tanto pela importância econômica mundial quanto pelo valor nutricional. O arroz é rico em carboidratos e fonte de proteína, com bom balanço de aminoácidos essenciais, apresentando alto teor de metionina e tendo a lisina como aminoácido limitante (NAVES e BASSINELLO, 2006; SILVA et al., 2009). Em contrapartida, o feijão é rico em lisina e deficiente em metionina. O grão de feijão é também fonte de carboidratos, fibras alimentares e pobre em gorduras. Mas, apesar da boa qualidade nutricional, o feijão apresenta atributos indesejáveis como fatores antinutricionais que podem ser reduzidos a partir do tratamento térmico, como no processo de extrusão. A utilização da extrusão também provoca alterações positivas nas características tecnológicas do feijão, favorecendo o uso das farinhas de feijão extrusadas em alimentos pré-processados (BATISTA et al., 2010; GOMES et al., 2006). Diante do exposto, o objetivo deste trabalho foi avaliar a estabilidade microbiológica, físico-química e sensorial, durante oito meses, de formulações de mistura para bolo sem glúten, elaboradas com farinhas de quirera de arroz crua e farinha de bandinha de feijão extrusada, assim como a qualidade dos bolos preparados a partir delas.

\section{Material e métodos}

A farinha de arroz crua foi processada no moinho Cyclotec ${ }^{\text {TM}} 1093$ (FOSS), a partir da quirera de arroz obtida no beneficiamento de variedades comerciais do arroz. Foi adicionada a essa farinha uma pequena proporção de amido de milho e denominada a farinha mista como FAC (farinha de quirera de arroz crua). A farinha de bandinha de feijão extrusada (FFE) foi processada seguindo-se a metodologia e os parâmetros predeterminados pela Embrapa Amazônia Oriental, Belém, Pará (CARVALHO et al., 2012b), tendo como ponto de partida a farinha de feijão crua (FFC) obtida da moagem da bandinha do feijão comum (Phaseolus vulgaris), oriunda do beneficiamento industrial de uma variedade comercial do feijão carioca.

As misturas para bolo foram elaboradas a partir de um tratamento controle (100\% farinha de trigo - mistura para bolo controle - MBC) composto por: açúcar refinado $(59,36 \%)$, farinha de trigo $(37,44 \%)$, fermento químico em pó $(2,97 \%)$ e sal $(0,23 \%)$. As misturas para bolo sem glúten testadas foram obtidas a partir de um delineamento inteiramente casualizado, com dois tratamentos de misturas para bolo (MB) com substituição total da farinha de trigo. O primeiro tratamento continha 45\% (MB45) de FFE e 55\% de FAC e o segundo, $75 \%$ (MB75) de FFE e $25 \%$ de FAC. Todos os ingredientes foram pesados separadamente e as misturas para bolo foram obtidas a partir da homogeneização manual, contínua, por três minutos, feita em sacos plásticos individualizados (capacidade de $0,5 \mathrm{~kg}$ ). Os produtos finais foram embalados em sacos plásticos de polietileno e, posteriormente, colocados em embalagem multicamada metalizada, selada em seladora simples de embalagens (Barbi M-300T, Brasil), para armazenamento em temperatura ambiente, protegidas da luz.

Para a avaliação da estabilidade das misturas para bolo também foram avaliadas as características físicas e sensoriais dos bolos prontos para consumo (BC - bolo controle; B45 - bolo com 45\% de FFE; B75 - bolo com $75 \%$ de FFE), preparados em batedeira planetária (Arno Deluxe SX80, Brasil) com a adição de ovos (165 g), margarina $(40 \mathrm{~g})$ e leite integral $(150 \mathrm{ml})$ às misturas para bolo, em uma única etapa, com exceção da clara do ovo utilizada para obter a clara em neve, que foi adicionada à massa manualmente, ao final. O forneamento ocorreu a $180^{\circ} \mathrm{C}$, por 35 minutos, em forno elétrico preaquecido (Layr - Luxo 2400 W).

Durante o experimento, as farinhas e as misturas para bolo foram armazenadas em local seco e arejado e o monitoramento periódico da temperatura e umidade ambiente foi realizado por meio de um termo-higrômetro digital (LR03_MN2400, Microzelle). As farinhas e misturas 
para bolo foram analisadas nos tempos $0,30,60,90$, 120, 150, 180, 210 e 240 dias, totalizando oito meses de armazenamento. A partir das misturas para bolo armazenadas, os bolos prontos para consumo foram preparados no dia das análises e analisados nos tempos 0, 30, 60, 105, 150, 195 e 240 dias. O tempo de análise diferenciado para os bolos prontos para consumo foi em função da disponibilidade dos provadores. O tempo máximo de análise foi estipulado com um mês a mais da vida de prateleira de algumas misturas para bolo comerciais (sete meses).

As análises realizadas periodicamente nas farinhas e misturas para bolo foram: análises microbiológicas, de umidade, de atividade de água, $\mathrm{pH}$, acidez total titulável e cor. A cor e as análises microbiológicas também foram avaliadas periodicamente nos bolos prontos para consumo, além do volume específico, da textura instrumental e da análise sensorial.

As análises microbiológicas foram determinadas segundo padrões estabelecidos pela resolução RDC n. 12 da Agência Nacional de Vigilância Sanitária do Ministério da Saúde - ANVISA (BRASIL, 2001) e seguiram os procedimentos descritos pela American Public Health Association (DOWNES e ITO, 2001) para cada microorganismo analisado - contagem de Bacillus cereus e coliformes a $45^{\circ} \mathrm{C}$ e ausência de Salmonella sp. em $25 \mathrm{~g}$ (BRASIL, 2001).

A umidade foi analisada por dessecação a $105^{\circ} \mathrm{C}$ até obtenção de peso constante. Para determinação da atividade de água (Aw) foi utilizado o equipamento portátil Aqualab, modelo CX-2-Decagon (USA), com início da leitura digital a $25^{\circ} \mathrm{C}$. Os valores do potencial hidrogeniônico $(\mathrm{pH})$ foram aferidos com leitura direta em potenciômetro digital (PG 1800, Gehaka). A acidez total titulável (ATT) foi determinada por titulação com $\mathrm{NaOH}$ 0,1 $\mathrm{N}$ até a solução atingir pH 8,0 em leitura no potenciômetro digital. Essas análises basearam-se nos métodos descritos por AOAC (HORWITZ, 2006). A cor foi avaliada em colorímetro Hunter Lab, modelo Color Quest $X E$, sendo os resultados expressos pelos parâmetros $L^{*}$, $a^{*}, b^{*}$ (HUNTERLAB, 1998).

A análise de volume específico (VE) dos bolos prontos para consumo foi conduzida pelo método de deslocamento de sementes de painço, utilizando-se cinco bolos de cada formulação e 17 medições do volume de cada bolo, a temperatura ambiente (CAMARGO et al., 2008). A textura foi medida em texturômetro TA.XT.plus. (Stable Micro Systems, UK), sempre 16 horas após o assamento dos bolos, conforme método adaptado de Gómez et al. (2010), utilizando-se 10 fatias $(20 \mathrm{~mm}$ ) de cada amostra para a análise de cisalhamento, calculando-se a força máxima para cisalhamento e a porcentagem de deformação, e 10 pedaços cilíndricos com 35 mm de diâmetro para a análise de compressão, estimando-se a tensão na ruptura e a energia de ruptura. Para a compressão foi utilizado o probe cilíndrico de
$50 \mathrm{~mm}$ perspex, com velocidade pré-teste de 1,0 mm/s, velocidade teste de $1,0 \mathrm{~mm} / \mathrm{s}$, velocidade pós-teste de $10,0 \mathrm{~mm} / \mathrm{s}$, tensão de $80 \%$, força de $3 \mathrm{~g}$, força de gatilho de 0,03 N, distância de $40 \mathrm{~mm}$. Para a análise de cisalhamento foram utilizados os mesmos parâmetros a partir do probe de corte - BSK. Esses parâmetros fornecem uma indicação da firmeza do bolo com base na força máxima que provoca a perda da estrutura da rede de bolo sem glúten. Ou seja, a tensão na ruptura é a força aplicada em uma área fixa do bolo necessária para causar o rompimento da estrutura do bolo em até $80 \%$ de deformação em relação à altura inicial do produto. A energia na ruptura reflete a quantidade de energia necessária para promover a ruptura do bolo, sendo assim, um parâmetro físico que depende da força e da respectiva deformação (energia = força $\mathrm{x}$ distância comprimida devido à deformação). Quanto maior a tensão ou energia, mais o bolo é resistente à deformação devido à aplicação de uma força em compressão, portanto, mais firme é a estrutura da massa.

A análise sensorial de aceitação dos bolos foi conduzida utilizando-se escala hedônica estruturada de nove pontos (STONE e SIDEL, 1985) para avaliação do aroma, sabor, textura e aparência. As amostras foram apresentadas aos provadores entre uma a três horas após o assamento, com massa em torno de 20 gramas, codificadas aleatoriamente com três dígitos, servidas em pratos descartáveis, sob luz vermelha e cabines individuais, com exceção para análise de aparência, que foi realizada em ambiente iluminado com luz do dia.

Para participação na pesquisa, todos os provadores assinaram o Termo de Consentimento Livre e Esclarecido submetido e aprovado pelo Comitê de Ética em Pesquisa da Universidade Federal de Goiás (protocolo: 273/2010). Participaram da análise sensorial um total de 402 provadores, sendo em média 57 consumidores potenciais do produto por etapa (variação de 44 a 67 provadores), conforme interesse e disponibilidade para participar das análises.

O índice de aceitabilidade (IA) foi calculado considerando-se a nota máxima alcançada pelo produto que estava sendo analisado como 100\% e a pontuação média, em \%, como o valor calculado de IA. O produto que atingiu um percentual igual ou maior que $70 \%$ foi considerado aceito pelos provadores (TEIXEIRA et al., 1987).

Os resultados foram gerados a partir da média de, pelo menos, três repetições de análise. Os dados foram submetidos à análise de regressão (linear, quadrática ou cúbica) e os efeitos principais da amostra e do tempo e sua interação foram analisados independentemente e considerados efeitos fixos. A análise de variância segundo procedimento de modelos lineares gerais (GLM), o teste múltiplo de comparação de médias de Duncan e a correlação de Pearson foram realizados de acordo com o Sistema de Análise Estatística, SAS 9.1 para Windows 
(SAS, 1990). A análise dos componentes de variância foi estimada com o PROC VARCOMP do SAS segundo o método recomendado da Máxima Probabilidade Restrita (REML).

\section{Resultados e discussão}

Nas Tabelas 1 e 2 apresentam-se, respectivamente, as médias gerais das características avaliadas para cada amostra e os parâmetros das equações de regressão linear, quadrática e cúbica para as classes, amostra e tempo de armazenamento nas quais os p-valores foram significativos $(p<0,05)$, indicando que há evidências de considerável tendência de relação entre os dados. Porém há casos em que não houve ajuste adequado do coeficiente de determinação $\left(R^{2}\right.$ aj. $\left.<0,70\right)$, sugerindo um baixo ajuste do modelo em relação à dispersão dos dados, o que dificulta a sua interpretação e predição, e, consequentemente, indica que o tempo de armazenamento não parece influenciar os parâmetros avaliados nas amostras. Devido a isso, os dados foram submetidos também à análise de variância e dos componentes da variância (Tabela 3), considerada mais interessante. Para os modelos em que o $\mathrm{R}^{2}$ ajustado foi superior a 0,70, o tempo de estocagem teve maior efeito sobre os parâmetros conforme a amostra, especialmente para atividade de água e textura instrumental.

A análise de variância demonstrou que os principais efeitos, amostras e tempo de armazenamento e sua interação foram altamente significativos $(p<0,0001)$ para a maioria dos componentes analisados, exceto para os atributos sensoriais dos bolos prontos (Tabela 3). As características avaliadas foram significativamente ( $p$ $<0,0001$ ) afetadas pela amostra, fator que contribuiu com $76 \%$ a $99 \%$ da variação total desses componentes para as farinhas, $50 \%$ a $99 \%$ para as misturas para bolo e $84 \%$ a $98 \%$ para os bolos prontos, ao invés do fator tempo, exceto para $\mathrm{pH}$ das misturas para bolo e para textura instrumental (deformação e força) e características sensoriais dos bolos prontos.

\subsection{Análises microbiológicas}

Os resultados das análises microbiológicas indicaram que todas as amostras das farinhas e das misturas para bolo, assim como dos bolos prontos para o consumo, mantiveram-se de acordo com os padrões estabelecidos pela RDC n. 12 da ANVISA (BRASIL, 2001), durante os oito meses de armazenamento. Os valores determinados para todas as amostras estiveram abaixo de 100 UFC/g, tanto para a contagem de Bacillus cereus quanto para contagem de coliformes a $45^{\circ} \mathrm{C}$, além da ausência da Salmonella sp. em $25 \mathrm{~g}$ da amostra. Isso provou que as matérias-primas (FAC, FFC e FFE) e as misturas para bolo (MBC, MB45 e MB75) podem ser armazenadas por até 240 dias à temperatura ambiente com segurança microbiológica para uso na alimentação humana (BRASIL, 1997).

Tabela 1. Médias gerais para as características analisadas das amostras de farinha, misturas para bolos e bolos prontos para consumo.

\begin{tabular}{|c|c|c|c|c|c|c|c|c|c|}
\hline \multirow[t]{2}{*}{ Análise\# } & \multicolumn{3}{|c|}{ Farinhas } & \multicolumn{3}{|c|}{ Misturas para bolo } & \multicolumn{3}{|c|}{ Bolos prontos } \\
\hline & FAC & FFC & FFE & MBC & MB45 & MB75 & BC & B45 & B75 \\
\hline Umidade & $9,23^{a}$ & $8,75^{b}$ & $5,78^{c}$ & $3,87^{x}$ & $3,07^{y}$ & $2,77^{2}$ & & & \\
\hline $\mathrm{pH}$ & $5,97^{c}$ & $6,22^{b}$ & $6,50^{a}$ & $7,03^{x}$ & $6,94^{y}$ & $6,97^{x y}$ & & & \\
\hline ATT (\%) & $0,19^{c}$ & $1,29^{a}$ & $1,07^{b}$ & $0,29^{z}$ & $0,40^{y}$ & $0,51^{x}$ & & & \\
\hline Aw & $0,47^{b}$ & $0,51^{\mathrm{a}}$ & $0,34^{c}$ & $0,56^{x}$ & $0,47^{y}$ & $0,44^{z}$ & & & \\
\hline $\operatorname{Cor}\left(L^{*}\right)$ & $90,5^{a}$ & $84,4^{\mathrm{b}}$ & $80,1^{c}$ & $88,4^{x}$ & $84,9^{y}$ & $82,4^{z}$ & $66,7^{p}$ & $55,0^{9}$ & $49,3^{r}$ \\
\hline $\operatorname{Cor}\left(a^{*}\right)$ & $-0,10^{c}$ & $1,41^{b}$ & $2,30^{\mathrm{a}}$ & $0,72^{z}$ & $1,40^{y}$ & $1,90^{x}$ & $2,96^{r}$ & $6,88^{9}$ & $7,92^{p}$ \\
\hline $\operatorname{Cor}\left(b^{\star}\right)$ & $6,10^{c}$ & $8,22^{b}$ & $10,92^{\mathrm{a}}$ & $10,53^{x}$ & $8,78^{z}$ & $9,93^{y}$ & $28,38^{p}$ & $18,84^{9}$ & $17,95^{r}$ \\
\hline $\operatorname{VE}\left(\mathrm{mL} \cdot \mathrm{g}^{-1}\right)$ & & & & & & & $4,47^{a}$ & $3,26^{b}$ & $2,91^{\mathrm{c}}$ \\
\hline Sabor & & & & & & & $7,67^{a}$ & $7,40^{b}$ & $7,18^{c}$ \\
\hline Textura & & & & & & & $7,97^{\mathrm{a}}$ & $7,36^{b}$ & $6,73^{c}$ \\
\hline Aroma & & & & & & & $7,61^{\mathrm{a}}$ & $7,32^{b}$ & $6,95^{c}$ \\
\hline Aparência & & & & & & & $8,26^{a}$ & $7,33^{b}$ & $6,56^{c}$ \\
\hline Força (N) & & & & & & & $3,04^{b}$ & $2,95^{b}$ & $3,71^{a}$ \\
\hline Deformação (\%) & & & & & & & $92,75^{a}$ & $87,34^{b}$ & $80,98^{c}$ \\
\hline $\begin{array}{l}\text { Tensão na } \\
\text { ruptura (kPa) }\end{array}$ & & & & & & & $33561^{c}$ & $57913^{b}$ & $81459^{a}$ \\
\hline $\begin{array}{l}\text { Energia na } \\
\text { ruptura (kJ) }\end{array}$ & & & & & & & $0,13^{c}$ & $0,26^{b}$ & $0,38^{a}$ \\
\hline
\end{tabular}

FAC - farinha de arroz crua; FFC - farinha de feijão crua; FFE - farinha de feiião extrusada; MBC - mistura para bolo controle; MB45 - mistura para bolo com 45\% de FFE; MB60 - mistura para bolo com 60\% de FFE; MB75 - mistura para bolo com $75 \%$ de FFE; BC - bolo controle; B45 - bolo com 45\% de FFE; B75 - bolo com 75\% de FFE; Aw - atividade de água; ATT - acidez total titulável; VE - volume específico; \# médias $(n \geq 3)$ seguidas de letras iguais na linha não diferem significativamente entre si $(p>0,05)$ pelo teste múltiplo de Duncan com amostra e tempo considerados fatores de variabilidade. 
Tabela 2. Parâmetros das equações de regressão propostas para o cálculo das características físico-químicas e sensoriais das farinhas e misturas para bolo em função do tempo.

\begin{tabular}{|c|c|c|c|c|c|c|c|}
\hline Análise & Amostra & a & b & c & d & $\mathrm{R}^{2}$ aj. & p valor* \\
\hline \multirow{3}{*}{$\mathrm{pH}$} & FAC & $-0,0350$ & 6,1120 & - & - & 0,40 & 0,0002 \\
\hline & FFC & $-0,0510$ & 6,4210 & - & - & 0,60 & $<0,0001$ \\
\hline & FFE & $-0,0210$ & 6,5850 & - & - & 0,23 & 0,0070 \\
\hline \multirow{6}{*}{ ATT } & FAC & 0,1350 & 0,0142 & - & - & 0,86 & $<0,0001$ \\
\hline & FFC & 0,0620 & 1,0385 & - & - & 0,88 & $<0,0001$ \\
\hline & FFE & 0,0050 & $-0,0160$ & 1,0150 & - & 0,60 & $<0,0001$ \\
\hline & $\mathrm{MBC}$ & 0,0087 & $-0,0630$ & 0,3446 & - & 0,62 & $<0,0001$ \\
\hline & MB45 & 0,0107 & $-0,0900$ & 0,5053 & - & 0,50 & 0,0003 \\
\hline & MB75 & 0,0167 & $-0,1456$ & 0,7120 & - & 0,54 & $<0,0001$ \\
\hline \multirow{6}{*}{ Aw } & FAC & 0,0020 & $-0,0170$ & 0,4815 & - & 0,70 & $<0,0001$ \\
\hline & FFC & 0,0015 & $-0,0135$ & 0,5271 & - & 0,70 & $<0,0001$ \\
\hline & FFE & 0,0040 & $-0,0233$ & 0,3516 & - & 0,81 & $<0,0001$ \\
\hline & $\mathrm{MBC}$ & 0,0023 & $-0,0308$ & 0,1104 & 0,4834 & 0,57 & 0,0144 \\
\hline & MB45 & 0,0033 & $-0,0255$ & 0,4956 & - & 0,77 & $<0,0001$ \\
\hline & MB75 & 0,0032 & $-0,0220$ & 0,4500 & - & 0,74 & $<0,0001$ \\
\hline \multirow{5}{*}{$\operatorname{Cor}\left(L^{*}\right)$} & FAC & 0,0400 & $-0,3040$ & 90,9260 & - & 0,40 & 0,0013 \\
\hline & FFC & 0,0180 & $-0,2160$ & 84,8500 & - & 0,32 & 0,0040 \\
\hline & FFE & 0,0290 & $-0,2344$ & 80,4000 & - & 0,21 & 0,0220 \\
\hline & $\mathrm{BC}$ & $-0,1834$ & 1,3480 & 65,0665 & - & 0,25 & 0,0303 \\
\hline & B45 & 0,7115 & 52,8850 & - & - & 0,28 & 0,0081 \\
\hline \multirow{4}{*}{$\operatorname{Cor}\left(a^{\star}\right)$} & FFC & $-0,0036$ & 0,0545 & 1,2750 & - & 0,84 & $<0,0001$ \\
\hline & FFE & 0,0210 & 2,2200 & - & - & 0,43 & 0,0001 \\
\hline & MB45 & 0,0140 & 1,3400 & - & - & 0,50 & $<0,0001$ \\
\hline & MB75 & 0,0200 & 1,8240 & - & - & 0,45 & $<0,0001$ \\
\hline \multirow{8}{*}{$\operatorname{Cor}\left(b^{\star}\right)$} & FAC & 5,8920 & 0,0524 & - & - & 0,83 & $<0,0001$ \\
\hline & FFC & 0,0340 & 8,0840 & - & - & 0,60 & $<0,0001$ \\
\hline & FFE & 0,0500 & 10,7100 & - & - & 0,40 & 0,0004 \\
\hline & MB45 & 0,0650 & 8,5150 & - & - & 0,55 & $<0,0001$ \\
\hline & MB75 & 0,0640 & 9,6710 & - & - & 0,43 & 0,0001 \\
\hline & $\mathrm{BC}$ & $-0,2340$ & 0,7970 & 29,0250 & - & 0,73 & $<0,0001$ \\
\hline & B45 & $-0,1809$ & 0,5020 & 19,6825 & - & 0,47 & 0,0013 \\
\hline & B75 & $-0,5930$ & 19,7240 & - & - & 0,33 & 0,0040 \\
\hline VE & B75 & 0,1107 & 2,5736 & - & - & 0,65 & 0,0180 \\
\hline \multirow{3}{*}{ Tensão } & $\mathrm{BC}$ & 671,5 & $-6791,6$ & 19508,6 & 21019,7 & 0,67 & 0,0420 \\
\hline & B45 & 803,0 & $-8532,3$ & 24862,5 & 42215,8 & 0,72 & 0,0284 \\
\hline & B75 & 1262,3 & $-12817,3$ & 37065,9 & 57362,7 & 0,89 & 0,0086 \\
\hline \multirow{2}{*}{ Energia } & $\mathrm{BC}$ & 0,0023 & $-0,0233$ & 0,0678 & 0,0796 & 0,79 & 0,0286 \\
\hline & B75 & 0,0062 & $-0,0625$ & 0,1816 & 0,2575 & 0,88 & 0,0107 \\
\hline Força & B75 & $-0,0736$ & 0,6685 & $-1,6004$ & 4,4582 & 0,97 & 0,0009 \\
\hline Textura & B75 & $-0,0111$ & 0,1598 & $-0,6899$ & 7,3917 & 0,83 & 0,0497 \\
\hline \multirow{5}{*}{ Umidade } & FFC & 0,0246 & $-0,2792$ & 0,7265 & 8,6340 & 0,64 & 0,0379 \\
\hline & FFE & 0,0287 & $-0,3454$ & 1,0991 & 5,0785 & 0,57 & 0,0223 \\
\hline & $\mathrm{MBC}$ & 0,0166 & $-0,2151$ & 0,6472 & 3,7740 & 0,72 & 0,0256 \\
\hline & MB45 & $-0,0114$ & 0,0355 & 3,1853 & - & 0,30 & 0,0064 \\
\hline & MB75 & $-0,0214$ & 0,1500 & 2,6607 & - & 0,16 & 0,0455 \\
\hline
\end{tabular}

Equação linear: $Y=a t+b$; equação quadrática: $Y=a t^{2}+b t+c$; equação cúbica: $Y=a t^{3}+b t^{2}+c t+d$; *significância do modelo $(p<0,05)$; FAC - farinha de arroz crua; FFC - farinha de feijão crua; FFE - farinha de feijão extrusada; MBC - mistura para bolo controle; MB45 - mistura para bolo com 45\% de FFE; MB75 - mistura para bolo com 75\% de FFE; BC - bolo controle; B45 - bolo com 45\% de FFE; B75 - bolo com 75\% de FFE; Aw - atividade de água; ATT - acidez total titulável; VE - volume específico. R² aj. - coeficiente de determinação. 
Tabela 3. Análise de variância e componentes da variância para as características analisadas das amostras de farinha, misturas para bolos e bolos prontos para consumo.

\begin{tabular}{|c|c|c|c|c|c|c|c|c|}
\hline \multirow[b]{2}{*}{ Amostra } & \multirow[b]{2}{*}{ Análise } & \multicolumn{3}{|c|}{ P valores } & \multicolumn{4}{|c|}{ Componentes de variância (\%) } \\
\hline & & $\begin{array}{c}\text { Amostra } \\
\text { (A) }\end{array}$ & $\begin{array}{c}\text { Tempo } \\
\text { (T) }\end{array}$ & $A \times T$ & A & $\mathbf{T}$ & $A \times T$ & Erro \\
\hline \multirow{7}{*}{ Farinhas } & Umidade & $<0,0001$ & $<0,0001$ & $<0,0001$ & 94,08 & 4,65 & 0,71 & 0,57 \\
\hline & $\mathrm{pH}$ & $<0,0001$ & $<0,0001$ & 0,0209 & 75,63 & 16,64 & 2,10 & 5,63 \\
\hline & ATT & $<0,0001$ & $<0,0001$ & $<0,0001$ & 95,84 & 2,44 & 1,63 & 0,09 \\
\hline & Aw & $<0,0001$ & $<0,0001$ & $<0,0001$ & 93,18 & 4,05 & 2,51 & 0,26 \\
\hline & $\operatorname{Cor}\left(L^{*}\right)$ & $<0,0001$ & $<0,0001$ & $<0,0001$ & 99,56 & 0,21 & 0,14 & 0,09 \\
\hline & $\operatorname{Cor}\left(a^{*}\right)$ & $<0,0001$ & $<0,0001$ & $<0,0001$ & 99,68 & 0,12 & 0,14 & 0,06 \\
\hline & $\operatorname{Cor}\left(b^{*}\right)$ & $<0,0001$ & $<0,0001$ & 0,0004 & 99,49 & 0,27 & 0,11 & 0,14 \\
\hline \multirow{7}{*}{ Misturas para bolo } & Umidade & $<0,0001$ & $<0,0001$ & 0,0026 & 73,56 & 17,91 & 3,18 & 5,35 \\
\hline & $\mathrm{pH}$ & 0,0524 & $<0,0001$ & 0,6769 & 3,75 & 51,57 & 0,00 & 44,69 \\
\hline & ATT & $<0,0001$ & $<0,0001$ & $<0,0001$ & 50,68 & 33,41 & 10,66 & 5,24 \\
\hline & Aw & $<0,0001$ & $<0,0001$ & $<0,0001$ & 77,60 & 2,84 & 19,20 & 0,36 \\
\hline & $\operatorname{Cor}\left(L^{*}\right)$ & $<0,0001$ & $<0,0001$ & 0,0718 & 99,28 & 0,41 & 0,06 & 0,26 \\
\hline & $\operatorname{Cor}\left(a^{*}\right)$ & $<0,0001$ & $<0,0001$ & $<0,0001$ & 99,11 & 0,51 & 0,24 & 0,13 \\
\hline & $\operatorname{Cor}\left(b^{\star}\right)$ & $<0,0001$ & $<0,0001$ & $<0,0001$ & 94,45 & 2,70 & 1,80 & 1,05 \\
\hline \multirow{4}{*}{ Bolos prontos } & VE & $<0,0001$ & $<0,0001$ & $<0,0001$ & 89,09 & 7,06 & 5,84 & 3,01 \\
\hline & $\operatorname{Cor}\left(L^{*}\right)$ & $<0,0001$ & $<0,0001$ & $<0,0001$ & 92,47 & 4,44 & 1,81 & 1,28 \\
\hline & $\operatorname{Cor}\left(a^{\star}\right)$ & $<0,0001$ & $<0,0001$ & 0,0007 & 97,81 & 0,60 & 0,76 & 0,83 \\
\hline & $\operatorname{Cor}\left(b^{\star}\right)$ & $<0,0001$ & $<0,0001$ & $<0,0001$ & 89,65 & 6,34 & 2,89 & 1,12 \\
\hline \multirow{4}{*}{ Textura } & Energia & $<0,0001$ & $<0,0001$ & $<0,0001$ & 85,59 & 5,47 & 3,54 & 5,41 \\
\hline & Tensão & $<0,0001$ & $<0,0001$ & $<0,0001$ & 84,28 & 5,71 & 3,84 & 6,17 \\
\hline & Deformação & $<0,0001$ & $<0,0001$ & $<0,0001$ & 29,77 & 38,30 & 10,25 & 21,67 \\
\hline & Força & $<0,0001$ & $<0,0001$ & $<0,0001$ & 27,00 & 22,41 & 29,57 & 21,02 \\
\hline \multirow{4}{*}{ Sensorial } & Aparência & $<0,0001$ & 0,0455 & 0,0395 & 31,68 & 0,13 & 1,00 & 67,18 \\
\hline & Textura & $<0,0001$ & 0,4873 & 0,0034 & 15,28 & 0,00 & 2,02 & 82,70 \\
\hline & Aroma & $<0,0001$ & 0,0046 & 0,005 & 5,01 & 0,43 & 2,26 & 92,31 \\
\hline & Sabor & $<0,0001$ & 0,0005 & 0,0018 & 2,81 & 0,72 & 2,68 & 93,78 \\
\hline
\end{tabular}

FAC - farinha de arroz crua; FFC - farinha de feijão crua; FFE - farinha de feijão extrusada; MBC - mistura para bolo controle; MB45 - mistura para bolo com 45\% de FFE; MB75 - mistura para bolo com 75\% de FFE; BC - bolo controle; B45 - bolo com 45\% de FFE; B75 - bolo com 75\% de FFE; Aw - atividade de água; ATT - acidez total titulável; VE - volume específico.

\subsection{Umidade relativa do ar e atividade de água}

A temperatura média do local de armazenamento das farinhas e misturas para bolo durante o estudo foi de $26,2{ }^{\circ} \mathrm{C}$, com máxima de $32,1^{\circ} \mathrm{C}$ e mínima de $22,4{ }^{\circ} \mathrm{C}$. A umidade relativa do ar média foi de $47,7 \%$, sendo a mínima de $25 \%$ e a máxima de $65 \%$.

Os percentuais de umidade apresentaram flutuações ao longo do armazenamento para as farinhas (Figura 1A), de modo que não foi possível estabelecer equações de regressão com bom ajuste e significância para predizer o comportamento das amostras durante a estimativa da estabilidade ao longo do armazenamento, exceto para as misturas para bolo (Tabela 1), indicando que o tempo não parece influenciar esse parâmetro para as farinhas. Apesar do baixo ajuste do coeficiente de determinação ( $R^{2}$ aj.), os modelos propostos para o cálculo de umidade das misturas para bolo durante o armazenamento foram significativos ( $p<0,05)$, sugerindo a possibilidade de se definir razoável tendência (quadrática) da influência do tempo sobre essa característica. Contudo, as variações da umidade durante os 240 dias foram baixas para todas as amostras analisadas, sendo que a maior diferença foi constatada para a FFE (1,54\%). Esses dados corroboram a pesquisa de misturas para bolos com farinha de yacon realizada por Borges et al. (2010), que concluíram que esse comportamento da umidade é uma característica indicadora de um bom armazenamento, pois durante toda a pesquisa os resultados atenderam ao preconizado pela RDC n. 263 para farinhas, na qual a umidade máxima aceitável é de 15\% (BRASIL, 2005). Essa estabilidade da umidade pode ser atribuída à baixa permeabilidade à umidade das embalagens utilizadas, sacos plásticos de polietileno e embalagem multicamada metalizada (BORGES et al., 2010).

$\mathrm{Na}$ Tabela 2, são propostas equações para o cálculo da Aw das farinhas e misturas para bolo em função do tempo de armazenamento. As equações são do tipo quadrática e verifica-se que em todas as amostras 

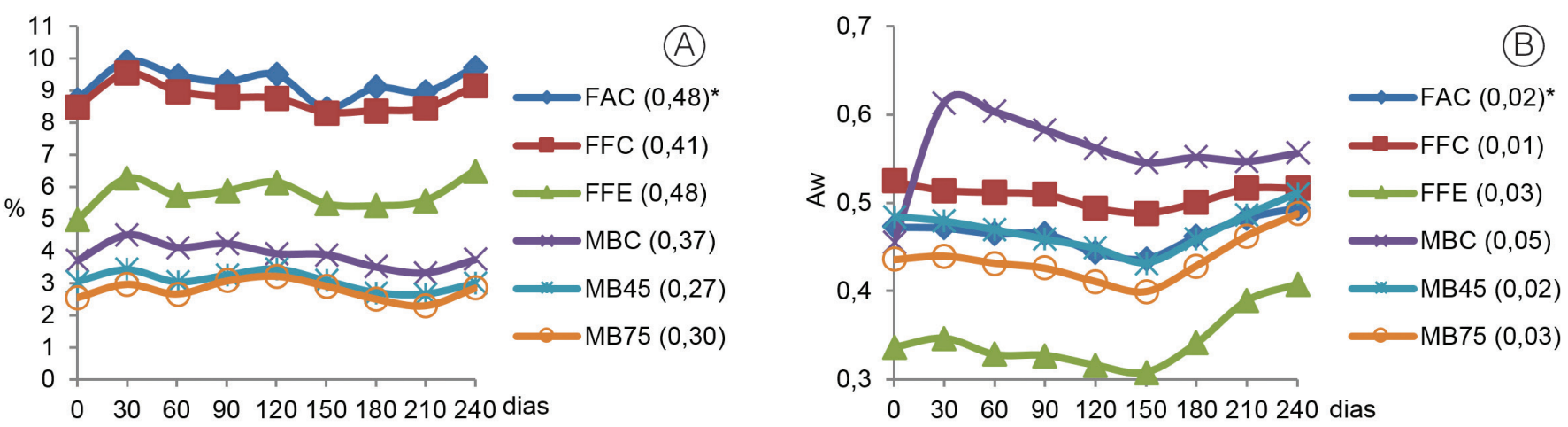

Figura 1. A - umidade (médias) das farinhas e misturas para bolo durante o armazenamento; B - atividade de água (médias) das farinhas e misturas para bolo durante o armazenamento. *Desvio padrão; FAC - farinha de arroz crua; FFC - farinha de feijão crua; FFE - farinha de feijão extrusada; MBC - mistura para bolo controle; MB45 - mistura para bolo com 45\% de FFE; MB75 - mistura para bolo com $75 \%$ de FFE.

as regressões apresentaram valores do coeficiente de determinação ( $R^{2}$ aj.) acima de 0,70 . Para a $M B C$ não houve bom ajuste do $R^{2}$ aj., para nenhuma das equações (linear, quadrática ou cúbica). Nota-se que o incremento de FFE promoveu diminuição significativa da umidade e da atividade de água das misturas para bolo (Tabela 1), sendo encontrada alta correlação positiva $(r=0,88)$ entre esses parâmetros para as amostras. Contudo, apesar da maior variação da Aw detectada para a MBC, de 0,15 (32,61\%), nenhuma das amostras estudadas atingiu os valores das atividades mínimas de água (Aw) para o desenvolvimento de bactérias $(0,90)$, leveduras $(0,80)$, bactérias halófilas $(0,65)$ e leveduras osmófilas $(0,62)$ (SARANTÓPOULOS e OLIVEIRA, 2001).

\subsection{Potencial hidrogeniônico e acidez total titulável}

Os resultados de $\mathrm{pH}$ das farinhas e das misturas para bolo também apresentaram muitas flutuações, não sendo possível estabelecer equações de regressão do pH com bom ajuste para predizer o comportamento das amostras durante o armazenamento (Tabelas 1 e 2 e Figura 2A). Para as farinhas houve uma tendência de diminuição no $\mathrm{pH}$ (FAC, de 6,19 para 5,81 ; FFC, de 6,46 para 5,99; e FFE, de 6,62 para 6,38), como ocorreu na farinha de trigo estudada por Miranda e El-Dash (2002), que foi de 6,5 a 6,1 em seis meses de armazenamento. Já para as misturas para bolo, apesar de o $\mathrm{pH}$ variar até 0,66 durante o estudo, ao final do período de armazenamento as misturas MBC, MB45 e MB75 apresentaram valores de pH semelhantes $(6,99,6,85$ e 6,88, respectivamente) aos resultados iniciais $(6,96,6,93$ e 6,74, respectivamente). De acordo com a análise dos componentes de variância, o tempo de armazenamento responde pela maior parte da variação do $\mathrm{pH}(51,57 \%)$ nas misturas para bolo (Tabela 3, $p<0,0001$ ).

A diminuição nos valores de $\mathrm{pH}$ das farinhas pode afetar a solubilidade das amostras, uma vez que, segundo Gomes et al. (2006), quanto menor o valor de pH, menor o índice de solubilidade. Sendo assim, é importante destacar que o processo de extrusão da farinha de feijão reduziu a variação no pH, podendo então favorecer a estabilidade da solubilidade da farinha de feijão durante o armazenamento.

Ao se compararem as Figuras $2 \mathrm{~A}$ e $2 \mathrm{~B}$, observa-se que conforme ocorre o aumento da ATT há uma diminuição do $\mathrm{pH}$ e vice-versa. Essa relação inversa entre $\mathrm{pH}$ e ATT também foi destacada por Miranda e El-Dash (2002) para farinha de trigo e por Ruiz et al. (2003) para farinha de arroz. Dentre as amostras, só foi possível determinar a regressão linear da ATT com bom ajuste do modelo para a FAC e a FFC ( $R^{2}$ aj. $=0,86$ e 0,88, respectivamente, Tabela 2), pois as demais farinhas e misturas para bolo apresentaram flutuações nos valores dessa análise, não se obtendo bom ajuste nos valores do coeficiente de determinação ( $R^{2}$ aj.), apesar dos respectivos modelos quadráticos significativos.

O tempo de armazenamento contribui grandemente para a variação encontrada no pH das misturas para bolo, conforme resultados (Tabela 3). A interação da amostra e tempo $(A \times T)$ teve efeito insignificante na variação do $\mathrm{pH}$ das farinhas, dado que sua variância foi menor do que aquela do erro experimental.

\subsection{Cor}

Para a maior parte das amostras, foram obtidas equações de regressão lineares ou quadráticas significativas para os parâmetros de cor $\left(L^{*}, a^{*} e b^{*}\right)$, porém foram obtidos ajustes adequados do coeficiente de determinação somente para cor $a^{*}$ (FFC) e cor $b^{*}$ (FAC e $\mathrm{BC}$ ), para as quais o tempo de armazenamento teve maior influência na variação (Tabela 2).

Tal como para o $\mathrm{pH}$, a interação da amostra e tempo $(A \times T)$ teve efeito insignificante na variação da cor $\left(b^{*}\right)$ das farinhas, dado que sua variância foi menor do que aquela do erro experimental (Tabela 3 ).

Fica evidente que a cor $L^{*}$ diminui com a incorporação de FFE, tornando o produto mais escuro 

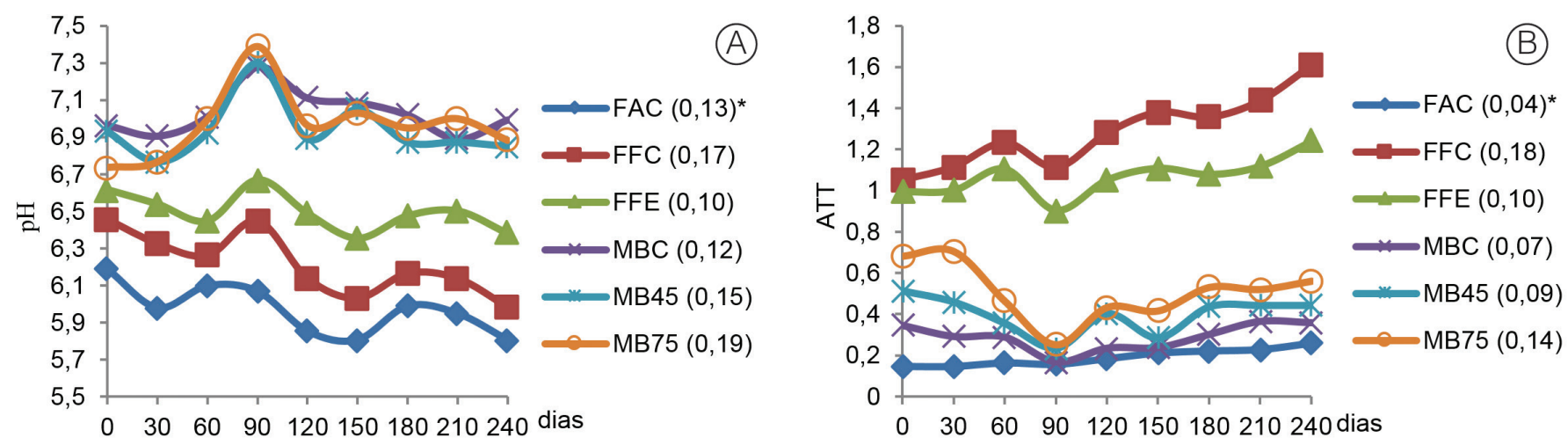

Figura 2. A - Potencial hidrogeniônico $(\mathrm{pH})$ das farinhas e misturas para bolo durante o armazenamento; B - acidez total titulável (ATT) das farinhas e misturas para bolo durante o armazenamento; valores correspondem às médias para as amostras em cada tempo. *Desvio padrão; FAC - farinha de arroz crua; FFC - farinha de feijão crua; FFE - farinha de feijão extrusada; MBC - mistura para bolo controle; MB45 - mistura para bolo com 45\% de FFE; MB75 - mistura para bolo com 75\% de FFE.

(também observado para os valores altos de $a^{*} e b^{*}$ ). As misturas para bolo e os bolos prontos (assados) seguem a mesma tendência, conforme se acrescenta farinha de feijão extrusada (Tabelas 1 e 3). Na análise de componentes de variância para os parâmetros de cor das amostras, observou-se que o tempo de armazenamento exerce pouca influência e que mais de $90 \%$ da variação é devida à amostra propriamente. Assim, pode-se esperar uma estabilidade do padrão de cor dos produtos finais a partir das misturas.

Foi obtida alta correlação interessante entre os atributos de cor para farinhas $\left(r=-0,99\right.$ entre $L^{*}$ e $a^{*}$, $r=-0,98$ entre $L^{*}$ e $b^{*}, r=0,97$ entre $a^{*}$ e $b^{*}$ ) e misturas para bolo $\left(r=-0,99\right.$ entre $L^{*}$ e $\left.a^{*}\right)$, assim como com a umidade. Em geral, percebe-se uma alta correlação negativa da luminosidade $\left(L^{*}\right)$ com os valores de $a^{*}$ das farinhas, misturas para bolo e bolos prontos $(r=-0,95)$.

$\mathrm{Na}$ literatura não são encontrados dados para comparação da cor em relação às misturas para bolo. Há alguns estudos que avaliam as alterações de cor de bolos prontos até no máximo 28 dias de armazenamento. O que se pode constatar é que o armazenamento do produto já pronto para o consumo sofre perda significativa da qualidade da cor, o que não ocorre quando estocado na forma seca, como misturas para bolo (BAIXAULI et al., 2008; MOSCATTO et al., 2004).

\subsection{Volume específico}

Com base nos dados da Tabela 2, foi obtida equação linear somente para VE do B75 $(p<0,05)$ com ajuste razoável. A maior parte da variação do VE observada é devida à amostra (89\%, Tabela 3), tendo baixa influência do tempo de armazenamento. 0 incremento de FFE na mistura para bolo parece provocar redução do $\operatorname{VE}(p<0,05$, Tabela 1$)$ dos bolos.

Para o perfil de VE (Figura 3), foi observado que ao final do estudo o BC e o B75 apresentaram um aumento percentual de $7,15 \%$ e $25,75 \%$, respectivamente,

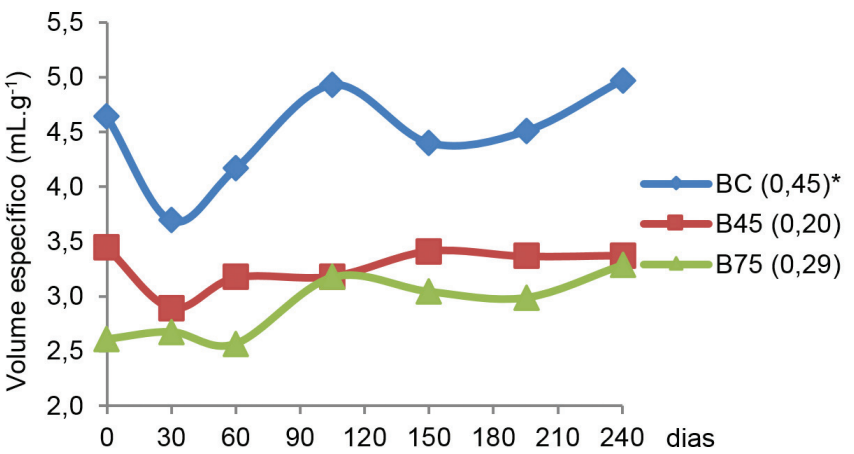

Figura 3. Volume específico (médias) dos bolos prontos para consumo durante o armazenamento. *Desvio padrão; BC - bolo controle; B45 - bolo com 45\% de FFE; B75 - bolo com $75 \%$ de FFE.

mostrando que apesar de apresentar menor VE em relação ao BC, o B75 obteve uma melhora do VE quase três vezes maior, proporcionalmente, em relação ao perfil do VE do BC durante o armazenamento das misturas para bolo. Considerando todas as variações de VE dos bolos B45 e B75 durante os oito meses deste estudo, em geral todos os valores encontrados são superiores aos relatados por Souza (2011) (1,2 a 1,9 ml. $\left.\mathrm{g}^{-1}\right)$ e por Gularte et al. (2012) $\left(\mathrm{VE}_{\text {médio }}=2,9 \mathrm{ml} \cdot \mathrm{g}^{-1}\right)$ para bolos sem glúten, com farinha de mandioca ou com diversas farinhas de leguminosas, respectivamente. Vale ressaltar que é importante a comparação dos bolos entre si e com os resultados de outros estudos, visto que não há um parâmetro definido na literatura para indicar qual o volume específico ideal de bolos.

\subsection{Textura dos bolos}

Os parâmetros de textura analisados para os bolos prontos para o consumo apresentaram flutuações nos resultados (Figura 4), sendo que mesmo com todos os bolos tendendo à estabilidade a partir do terceiro mês para a análise de compressão, não foi possível 

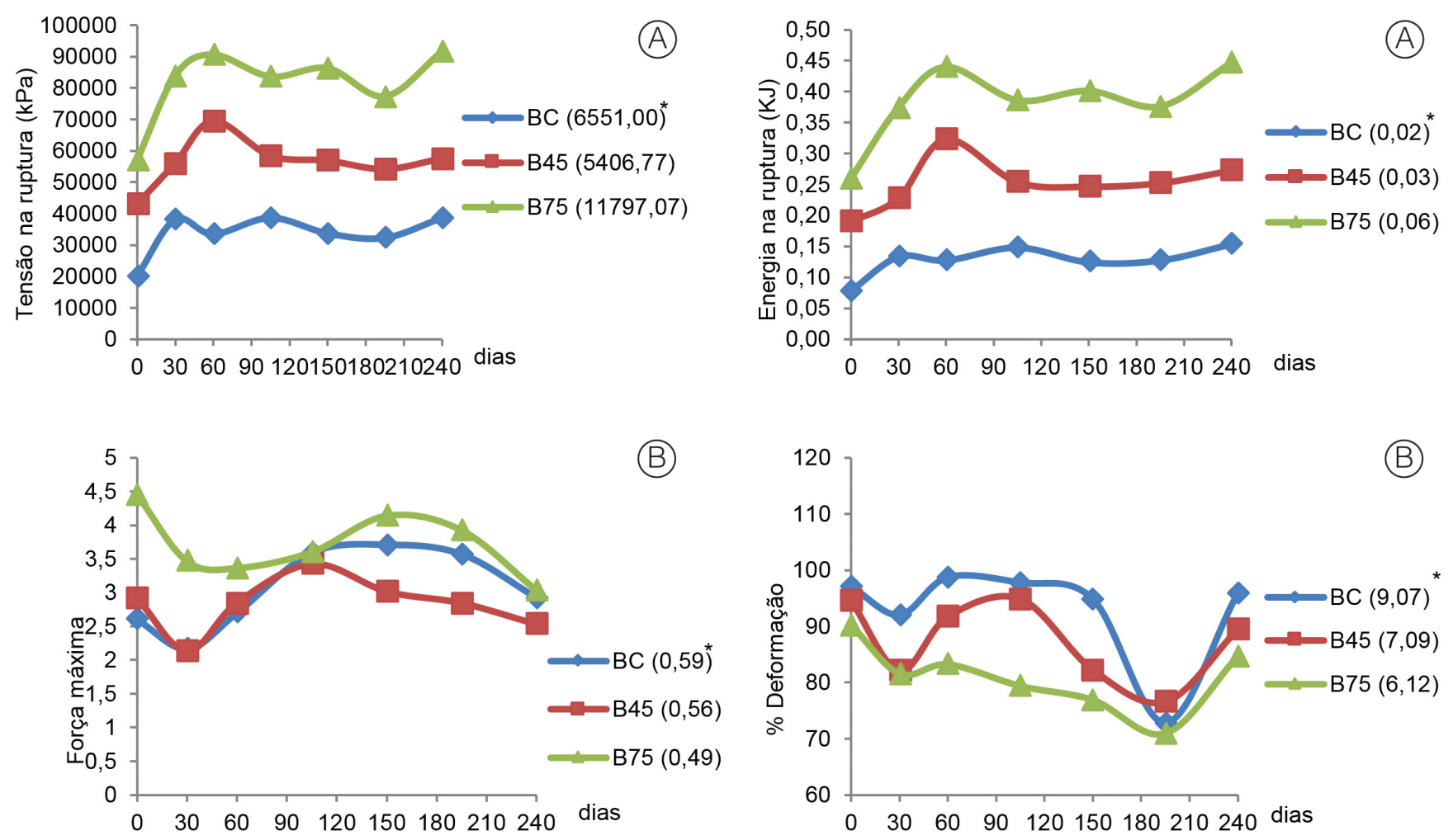

Figura 4. Médias da análise de textura instrumental (compressão - 4A e cisalhamento - 4B) dos bolos prontos para consumo durante o armazenamento das misturas para bolo. *Desvio padrão; BC - bolo controle; B45 - bolo com $45 \%$ de FFE; B75 - bolo com $75 \%$ de FFE.

estabelecer equação de regressão significativa com $\mathrm{R}^{2}$ ajustado para todas as amostras e parâmetros (Tabela 2). O aumento significativo da tensão nos 60 primeiros dias de armazenamento, para todos os bolos, pode ser devido às interações entre o fermento químico e os demais ingredientes das misturas para bolo. A partir do momento em que o fermento químico é misturado aos demais ingredientes, podem se iniciar suas reações, ainda que em baixa escala, devido a baixa umidade e temperatura ambiente, mas já diminuindo sua posterior ação durante a cocção dos bolos (CANELLA-RAWLS, 2006; DAMODARAN et al., 2010).

Vale destacar ainda que a adição gradual de FFE induziu a um aumento significativo $(p<0,05)$ nos valores de tensão na ruptura e da energia de ruptura dos bolos (Tabela 1, Figura 4), indicando que a presença de feijão na formulação tende a elevar a firmeza do produto. A característica das leguminosas de tornar maior a dureza de bolos também foi relatada por Gularte et al. (2012), que obtiveram aumento significativo da dureza e mastigabilidade dos bolos elaborados com feijão, grão de bico e ervilha. Bassinello et al. (2010) também constataram elevação da firmeza de bolos com o acréscimo de farinha de arroz cru e/ou farinha de feijão cozido.

Há diversas pesquisas que analisam a estabilidade de bolos assados armazenados e, de forma geral, os bolos já começam a perder significativamente a qualidade da textura a partir do segundo dia de armazenamento (BAIXAULI et al., 2008; GÓMEZ et al., 2010; MOSCATTO et al., 2004), apresentando textura indesejável entre 4 e 28 dias. Logo, o armazenamento dos bolos na forma de misturas para bolo viabiliza a comecialização dos produtos por maior tempo e com melhores características tecnológicas.

O tempo de armazenamento contribui significativamente para a variação encontrada na deformação do bolo pronto, conforme resultados (Tabela 3). Por outro lado, a interação $(A \times T)$ foi significativa e relativamente alta para o parâmetro de textura instrumental, força, em bolos prontos, indicando que as amostras respondem diferentemente nesse quesito ao longo do tempo, resultando em grandes flutuações (instabilidade) com o armazenamento.

\subsection{Aceitação sensorial}

Os gráficos que representam a evolução dos resultados da análise sensorial durante o estudo encontram-se na Figura 5. Durante todo o estudo, nenhuma das amostras recebeu notas médias inferiores ao escore 6 , indicando que nesse período todas as 

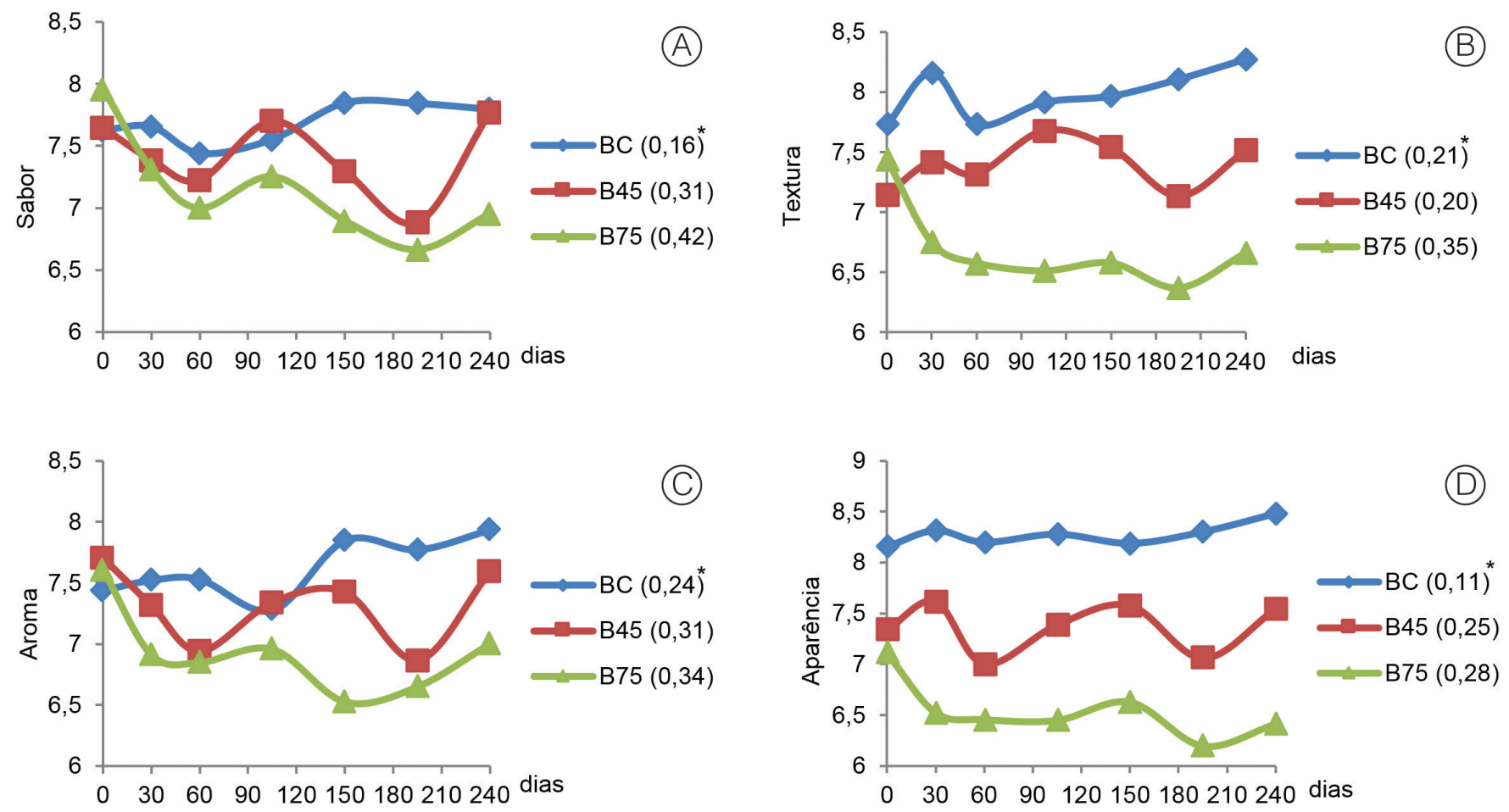

Figura 5. Médias da análise sensorial (sabor - 5A, textura - 5B, aroma - 5C e aparência - 5D) dos bolos prontos para consumo durante o armazenamento das misturas para bolo. *Desvio padrão; BC - bolo controle; B45 - bolo com 45\% de FFE; B75 - bolo com $75 \%$ de FFE.

amostras foram aceitas pelos provadores para todos os atributos analisados.

Quanto ao sabor, observa-se que até os 105 dias de armazenamento das misturas para bolo, os bolos elaborados obtiveram notas médias próximas entre as três formulações, inclusive com destaque para o tempo zero, no qual as notas superiores foram atribuídas aos bolos B45, sem diferença significativa, e B75, com diferença significativa $(p<0,05)$ em relação ao bolo BC. Ressalta-se ainda que, na maior parte do tempo, o B45 obteve notas superiores ao escore 7 (gostei moderadamente) e que, apesar de mais baixas, as notas do B75 foram superiores ao escore 6 (gostei ligeiramente), indicando a boa aceitabilidade desses bolos. Além disso, todas as formulações testadas tiveram suas notas, durante o período de armazenamento, próximas ao constatado na literatura para diversos bolos com substituição da farinha de trigo, as quais variam de 6,3 a 7,3 (MOSCATTO et al., 2004; SILVA et al., 2009; SOUZA, 2011; VILLANUEVA e TRINDADE, 2010).

Para a análise de textura foi observado também que todos os bolos chegaram ao fim do experimento com notas superiores a 6, favorecendo a sua aceitabilidade. Destaca-se ainda que, ao final do experimento, o B75 apresentou notas de textura semelhantes aos bolos sem glúten à base de farinha de mandioca desenvolvidos por Souza (2011) - média de 6,68 - enquanto que o B45 se aproximou da nota 7,30, média relatada por
Moscatto et al. (2004) para bolos com farinha de yacon e inulina e por Wang et al. (2005) para bolos com farinha de trigo e soja extrusada.

Os aromas dos bolos BC e B45 mantiveram sua avaliação média acima do escore 7 (gostei moderadamente) durante todo o estudo, com exceção dos tempos 60 e 195 dias para o B45, cujas médias foram inferiores, contudo muito próximas de 7 (6,94 e 6,87 , respectivamente). O bolo B75 teve uma boa avaliação inicial $(7,60)$, estando na média dos demais bolos, mas finalizou com a média significativamente $(p<0,05)$ inferior $(7,00)$ aos bolos BC $(7,93)$ e B45 $(7,59)$. O feijão cozido possui aroma característico, o qual pode ter sido percebido durante a análise sensorial e ter afetado a aceitação do bolo, uma vez que a população brasileira está habituada a consumir o feijão quase que exclusivamente em preparações salgadas, além de ser o aroma da farinha de trigo o mais reconhecido em bolos.

A diminuição das notas de todos os atributos sensoriais do bolo B75 durante armazenamento pode ser explicada pela diferença na forma de servir as amostras. No tempo zero, cada amostra foi avaliada em um período diferente, evitando-se ao máximo a comparação entre as formulações pelos provadores. Já nos demais tempos todas as amostras (BC, B45 e B75) foram servidas num único momento da análise e, mesmo que de forma monádica, houve maior possibilidade de ocorrerem comparações entre as amostras. Além disso, 
em cada tempo analisado ao longo do armazenamento participaram diferentes provadores, o que também pode justificar as diferenças significativas entre as médias de uma mesma amostra, por ser uma análise subjetiva (TEIXEIRA et al., 1987).

A variação do número de provadores (44/67) na análise sensorial pode explicar os resultados obtidos para os atributos sensoriais. Entretanto, os dados indicam que o tempo de estocagem das misturas para bolo não foi o principal fator a definir a percepção/qualidade sensorial ou a aceitabilidade dos bolos, sugerindo que não houve mudanças indesejáveis, por exemplo, quanto à oxidação ou rancidificação do produto perceptíveis durante o período analisado (Tabela 3). Portanto, acredita-se que é possível definir um prazo de validade relativamente longo na embalagem do produto, sem risco de deterioração ou perda de qualidade.

Para a avaliação da aparência pode-se destacar que, aos 240 dias de armazenamento das misturas para bolos, o B75 $(6,42)$ apresentou nota semelhante, e os bolos $\mathrm{BC}(8,48)$ e $\mathrm{B} 45(7,54)$ notas superiores às médias de outros bolos testados por Moscatto et al. (2004) e Silva et al. (2009) com a substituição parcial da farinha de trigo, cuja variação das médias foi de 6,4 a 6,6. Além disso, o B45 apresentou nota próxima ao constatado por Souza (2011) - 7,0 - e Wang et al. (2005) - 7,73.

Villanueva e Trindade (2010) armazenaram por 180 dias cupcakes de chocolate, registrando notas inferiores ao escore 6 (gostei ligeiramente) para textura, aroma e qualidade total a partir do $60^{\circ} \mathrm{dia}$, o que indica uma rejeição do produto. Isso reforça a vantagem de se adotar o armazenamento do produto panificado na forma de misturas para bolo em relação aos bolos prontos para consumo, uma vez que, conforme observado no presente trabalho, houve aceitação (médias > 6) para todos os atributos sensoriais dos bolos preparados a partir das misturas armazenadas até o final do experimento.

De modo geral, houve diferença significativa $(p<0,05)$ entre as notas dos atributos para os diferentes bolos (BC > B45 > B75, Tabela 1), porém todos podem ser considerados com boa aceitação. Os índices de aceitabilidade referentes a todo o período de armazenamento das misturas para bolo apresentaram excelentes resultados, todos superiores a $85 \%$, sendo $93,05 \%$ para o $\mathrm{BC}, 96,36 \%$ para o $\mathrm{B} 45$ e $85,79 \%$ para o B75. Tais resultados demonstram que todos os bolos testados apresentaram um bom potencial para consumo, uma vez que os resultados do IA para os diferentes atributos foram acima de 70\%, considerados, portanto, satisfatórios (TEIXEIRA et al., 1987).

\section{Conclusões}

As misturas para bolo sem glúten com farinhas de quirera de arroz crua e de bandinha de feijão extrusada, adequadamente embaladas, mantiveram razoavelmente suas características físico-químicas durante os 240 dias de armazenamento à temperatura ambiente, permitindo a elaboração de bolos prontos para consumo em condições seguras e com qualidades sensorial e tecnológica aceitáveis. Todas as formulações testadas tiveram boa aceitação sensorial, superior a $85 \%$, até o oitavo mês de estocagem.

As matérias-primas utilizadas neste estudo e o armazenamento das misturas para bolo também asseguram a qualidade microbiológica dos produtos finais para consumo, conforme padrões microbiológicos exigidos pela legislação.

Conclui-se, portanto, que é viável e recomendável a elaboração de bolos sem glúten contendo até $75 \%$ de farinha de feijão extrusada em relação às demais farinhas da preparação.

\section{Agradecimentos}

Os autores agradecem aos pesquisadores Dr. Eduardo Eifert, Dr. Dave Oomah e ao doutorando Ivanildo Ramalho pelo apoio às análises estatísticas.

\section{Referências}

BAIXAULI, R.; SALVADOR, A.; FISZMAN, S. M. Textural and colour changes during storage and sensory shelf life of muffins containing resistant starch. European Food Research and Technology, Berlin, v. 226, n. 3, p. 523-530, 2008. http://dx.doi. org/10.1007/s00217-007-0565-4

BASSINELLO, P. Z.; CARVALHO, R. N.; ALMEIDA, R. P.; ARAÚJO, M. R.; $\mathrm{COBUCCI}$, R. M. A. Desenvolvimento de mistura para bolo com farinhas de quirera de arroz e bandinha de feijão. Santo Antônio de Goiás: Embrapa Arroz e Feijão, 2010. (Comunicado Técnico 193).

BATISTA, K. A.; PRUDÊNCIA, S. H.; FERNANDES, K. F. Changes in the biochemical and functional properties of the extrused hard-to-cook cowpea (Vigna unguiculata L. Walp). International Journal of Food Science and Technology, Oxford, v. 45, n. 4, p. 794-799, 2010. http://dx.doi.org/10.1111/j.13652621.2010.02200.x

BORGES, A. M.; PEREIRA, J.; SILVA JÚNIOR, A.; LUCENA, E. M. P.; SALES, J. C. Estabilidade da pré-mistura de bolo elaborada com $60 \%$ de farinha de banana verde. Ciência e Agrotecnologia, Lavras, v. 34, n. 1, p. 173-181, 2010. http:// dx.doi.org/10.1590/S1413-70542010000100022

BORGES, J. T. S.; PIROZI, M. R.; LUCIA, S. M. D.; PEREIRA, P. C.; MORAIS, A. R. F.; CASTRO, V. C. Utilização de farinha mista de aveia e trigo na elaboração de bolos. Boletim CEPPA, Curitiba, v. 24, n. 1, p. 145-162, 2006.

BRASIL. Ministério da Saúde. Portaria $n^{\circ} 326$, de 30 de julho de 1997. Aprova o regulamento técnico sobre as condições higiênico-sanitárias e de boas práticas de fabricação para estabelecimentos produtores/industrializadores de alimentos. Diário Oficial [da] República Federativa do Brasil, Poder 
Estabilidade microbiológica e físico-química de misturas para bolo sem glúten e qualidade dos bolos prontos para consumo GOMES, L. O. F. et al.

Executivo, Brasília, DF, v. 135, n. 146, p. 16560-16566, 1 ago. 1997. Seção 1

BRASIL. Ministério da Saúde. Agência Nacional de Vigilância Sanitária. Resolução RDC n 12, de 02 de janeiro de 2001. Aprova o regulamento técnico sobre os padrões microbiológicos para alimentos. Diário Oficial [da] República Federativa do Brasil, Poder Executivo, Brasília, DF, v. 139, n. 7-E, p. 45-53, 10 jan. 2001. Seção 1.

BRASIL. Ministério da Saúde. Agência Nacional de Vigilância Sanitária. Resolução RDC n² 263, de 22 de setembro de 2005. Aprova o regulamento técnico para produtos de cereais, amidos, farinhas e farelos. Diário Oficial [da] República Federativa do Brasil, Poder Executivo, Brasília, DF, v. 142, n. 184, p. 368-369, 23 set. 2005. Seção 1.

CAMARGO, K. F.; LEONEL, M.; MISCHAN, M. M. Produção de biscoitos extrusados de polvilho azedo com fibras: efeito de parâmetros operacionais sobre as propriedades físicas. Ciência e Tecnologia de Alimentos, Campinas, v. 28, n. 3, p. 586-591, 2008. http://dx.doi.org/10.1590/S0101-20612008000300013

CANELLA-RAWLS, S. Pão: arte e ciência. 2. ed. rev. São Paulo: Senac, 2006. 314 p.

CARVALHO, A. V.; BASSinello, P. Z.; MATTIETTO, R. A.; CARVALHO, R. N.; RIOS, A. O.; SECCADIO, L. L. Processamento e caracterização de snack extrudado a partir de farinhas de quirera de arroz e de bandinha de feijão. Brazilian Journal of Food Technology, Campinas, v. 15, n. 1, p. 72-83, 2012a. http:// dx.doi.org/10.1590/S1981-67232012000100008

A, A. V.; RIOS, A. O.; BASSINELLO, P. Z.; FERREIRA, T. F. Efeito dos parâmetros de extrusão termoplástica sobre as propriedades tecnológicas de farinhas pré-cozidas elaboradas com arroz e feijão. Brazilian Journal of Food Technology, Campinas, v. 15, n. 4, p. 333-342, 2012b. http://dx.doi.org/10.1590/S198167232012005000029

DAMODARAN, S.; PARKIN, K. L.; FENNEMA, O. R. Química de alimentos de Fennema. 4. ed. Porto Alegre: Artmed, 2010. $900 \mathrm{p}$.

DOWNES, F. P.; ITO, K. (Ed.). Compendium of methods for the microbiological examination of foods. 4. ed. Washington: American Public Health Association, 2001. 676 p.

GOMES, J. C.; SILVA, C. O.; COSTA, N. M. B.; PIROZI, M. R. Desenvolvimento e caracterização de farinhas de feijão. Revista Ceres, Viçosa, v. 53, n. 309, p. 548-558, 2006.

GÓMEZ, M.; RUIZ-PARÍS, E.; OLIETE, B.; PANDO, V. Modeling of texture evolution of cakes during storage. Journal of Texture Studies, Trumbull, v. 41, n. 1, p. 17-33, 2010. http://dx.doi. org/10.1111/j.1745-4603.2009.00210.x

GULARTE, M. A.; GÓMEZ M.; ROSELL, C. M. Impact of legume flours on quality and in vitro digestibility of starch and protein from gluten-free cakes. Food and Bioprocess Technology, United States, v. 5, n. 8, p. 3142-3150, 2012. http://dx.doi. org/10.1007/s11947-011-0642-3

HORWITZ, W. (Ed.). ASSOCIATION OF OFFICIAL ANALYTICAL CHEMISTS - AOAC. Official methods of analysis of AOAC International. 18 ${ }^{\text {th }}$ ed. Gaithersburg: AOAC International, 2006.

HUNTERLAB. User's manual with universal software versions 3.5. Reston: Hunterlab, 1998.
MIRANDA, M. Z.; EL-DASH, A. Farinha integral de trigo germinado. 3. Características nutricionais e estabilidade ao armazenamento. Ciência e Tecnologia de Alimentos, Campinas, v. 22, n. 3, p. 216-223, 2002. http://dx.doi. org/10.1590/S0101-20612002000300003.

MOSCATTO, J. A.; PRUDÊNCIO-FERREIRA, S. H.; HAULY, M. C. O. Farinha de yacon e inulina como ingredientes na formulação de bolo de chocolate. Ciência e Tecnologia de Alimentos, Campinas, v. 24, n. 4, p. 634-640, 2004. http://dx.doi. org/10.1590/S0101-20612004000400026

NAVES, M. M. V.; BASSINELLO, P. Z. Importância na nutrição humana. In: SANTOS, A. B.; STONE, L. F.; VIEIRA, N. R. A. (Ed.). A cultura do arroz no Brasil. 2. ed. Santo Antônio de Goiás: Embrapa Arroz e Feijão, 2006. p. 17-33.

RUIZ, A. W.; BONATO, S. R.; ARRIECHE, L. S.; ALVES, F. V. Caracterização da farinha pré-gelatinizada de arroz integral produzida a partir de grãos quebrados. Vetor, Rio Grande do Sul, v. 13, p. 25-46, 2003.

SARANTÓPOULOS, C. I. G. L.; OLIVEIRA, E. C. Requisitos de conservação de alimentos em embalagens flexíveis. Campinas: CETEA/ITAL, 2001. 215 p.

SAS INSTITUTE - SAS. SAS/STAT user's guide. Version 6. 4th ed. Cary: SAS Institute, 1990. p. 891-996.

SILVA, R. F.; ASCHERI, J. L. R.; PEREIRA, R. G. F. A.; MODESTA, R. D. C. Aceitabilidade de biscoitos e bolos à base de arroz com café extrusados. Ciência e Tecnologia de Alimentos, Campinas, v. 29, n. 4, p. 815-819, 2009. http://dx.doi. org/10.1590/S0101-20612009000400018

SOUZA, T. A. C. Segurança microbiológica dos resíduos sólidos de fecularia e aplicação em bolos para a alimentação humana. 2011. 91 f. Dissertação (Mestrado em Ciência e Tecnologia de Alimentos)-Escola de Agronomia e Engenharia de Alimentos, Universidade Federal de Goiás, Goiânia, 2011.

STONE, H.; SIDEL, J. L. Affective testing. In: STONE, H.; SIDEL, J. L. Sensory evaluation practices. Boca Raton: Academic Press, 1985. p. 227-252. http://dx.doi.org/10.1016/B978-0-12672480-6.50011-1

TEIXEIRA, E.; MEINERT, E. M.; BARBetTA, P. A. Métodos sensoriais. In: TEIXEIRA, E.; MEINERT, E. M.; BARBETTA, P. A. Análise sensorial de alimentos. Florianópolis: Editora UFSC, 1987. p. 66-119.

VILLANUEVA, N. D. M.; TRINDADE, M. A. Estimating sensory shelf life of chocolate and carrot cupcakes using acceptance tests. Journal of Sensory Studies, Trumbull, v. 25, n. 2, p. 260-279, 2010. http://dx.doi.org/10.1111/j.1745-459X.2009.00256.x

WANG, S. H.; ROCHA, G. O.; NASCIMENTO, T. P.; ASCHERI, J. L. R.; OLIVEIRA, A. Características sensoriais de bolos esponja preparados com farinhas de trigo e soja extrusadas em diferentes parâmetros de extrusão. Alimentos e Nutrição, Araraquara, v. 16, n. 4, p. 369-376, 2005. 